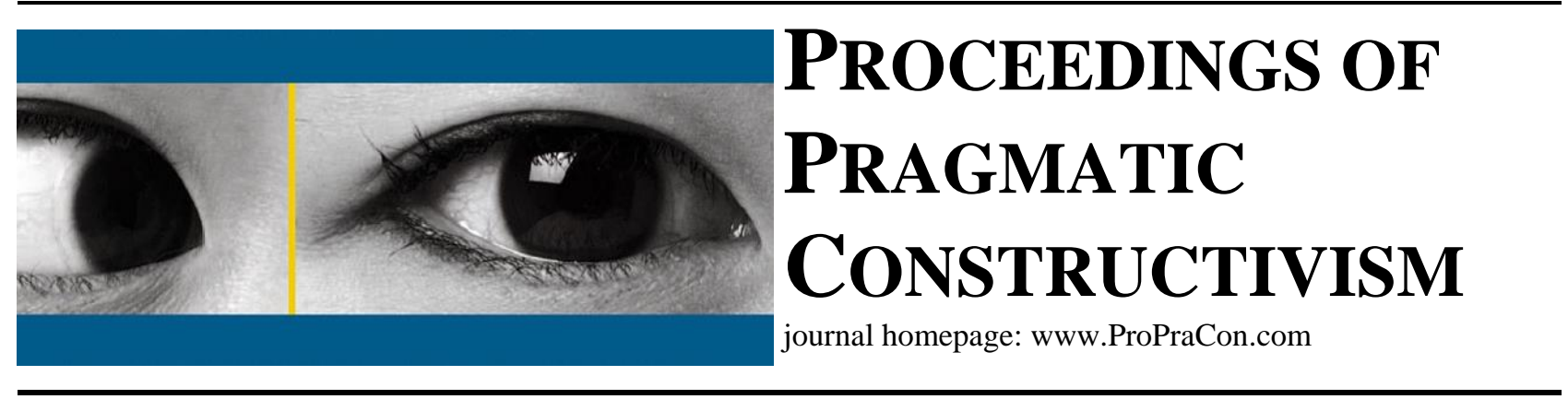

\title{
A pragmatic constructivist approach toward Higher Education management policies - The case of English medium instruction at Aarhus University
}

\author{
Klarissa Lueg \\ Assistant Professor of Knowledge Communication \\ Aarhus University; School of Business and Social Sciences; Department of Business Communication \\ Jens Christian Skous Vej 4; 8000 Aarhus C; Denmark; lueg@asb.dk \\ Rainer Lueg \\ Associate Professor of Management Accounting and Control \\ Aarhus University; School of Business and Social Sciences; Department of Economics and Business \\ Fuglesangs Allé 4, 8210 Aarhus V, Denmark; rlueg@asb.dk
}

\begin{abstract}
This paper specifically highlights that discussion on instruction language does not account for stratum specific study strategies. It was presented at the 3rd Actor-reality conference, Aarhus University, October 23-25, 2013.
\end{abstract}

Keywords: English medium instruction; higher education; university management. 


\section{A pragmatic constructivist approach toward Higher Education management policies}

The case of English medium instruction at Aarhus University

\section{Motivation \& Background}

Language discussion does not account for stratum specific study strategies

\section{Elite Discourse}

- "Language of higher education" (Coleman 2004)

- „Near-necessity of English proficiency for graduate employabilty" (Costa/Coleman 2012)

- Career opportunity for students (Byun et al. 2011)

- Students need „international competencies" in order "to compete on

Research on Social Background

- Why do students self select against EMI?

- Why do students chose EMI? the global job market“ (AU 2012)

- Split between „English-oriented elite“ and Danish majority (Harder 2009) 


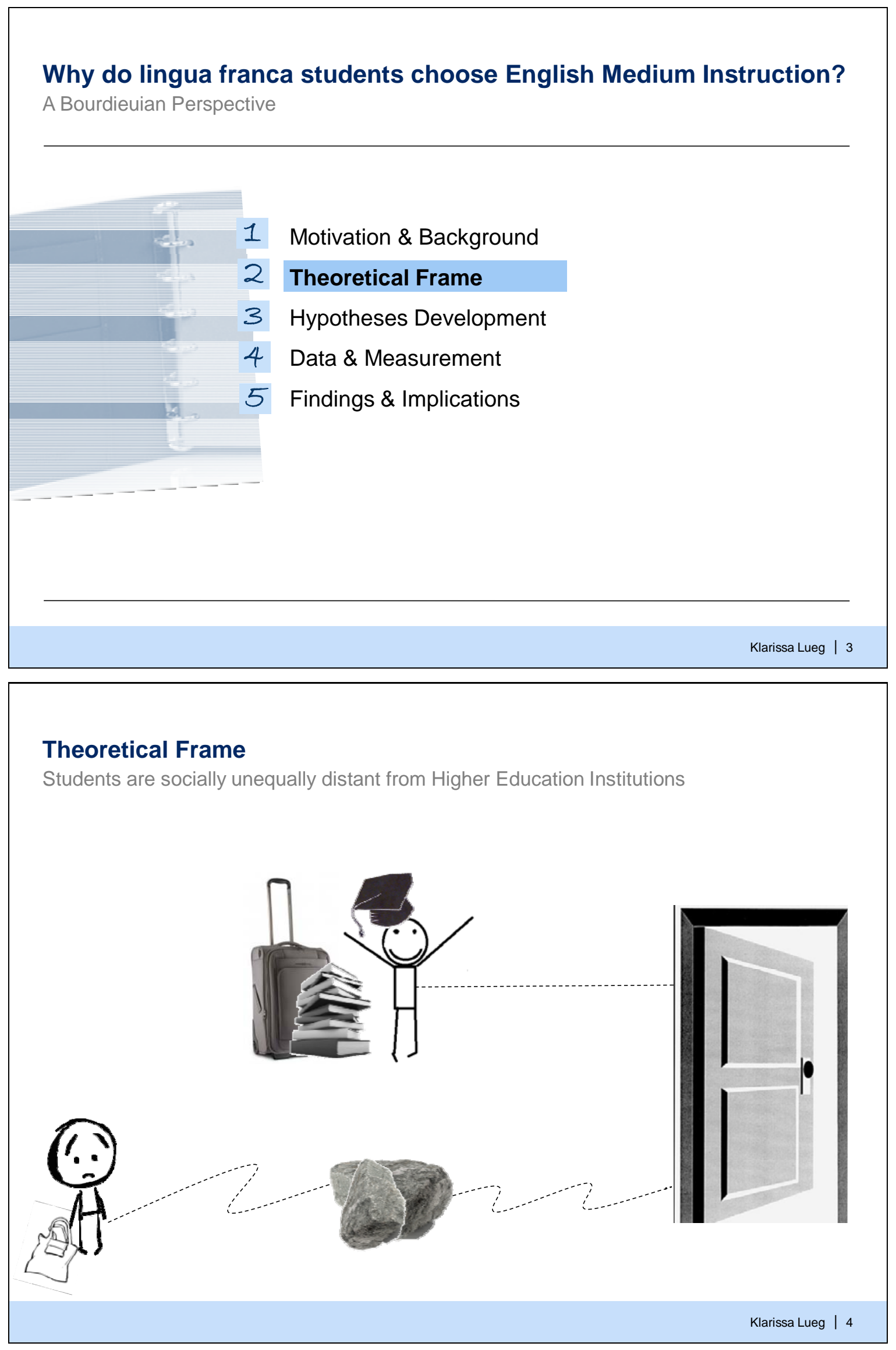




\section{Why do lingua franca students choose English Medium Instruction?}

\section{A Bourdieuian Perspective}

\section{Motivation \& Background}

2 Theoretical Frame

3 Hypotheses Development

4 Data \& Measurement

5 Findings \& Implications

\section{Hypotheses development}

We derive hypotheses relating to social background, cultural capital and habitus

H1a: The higher the social background, the more likely the choice of EMI

H1b: The higher the social background, the higher the expectation of English as working language

H1c: The higher the social background, the higher the expected job advantage from EMI

H1d: The higher the social background, the higher the perceived English proficiency

H2a: The expectation of English as working language positively impacts the choice of EMI

H2b: The expectation of English as working language positively impacts the expected job advantages

H3: The higher the expected job advantages, the more likely the choice of EMI

H4a: The higher the English proficiency, the more likely the choice of EMI

H4b: The higher the English proficiency, the lower the barriers to choose EMI

H5: The higher the expectation of barriers (inferior use of time, lower grade), the less likely is the choice of EMI.

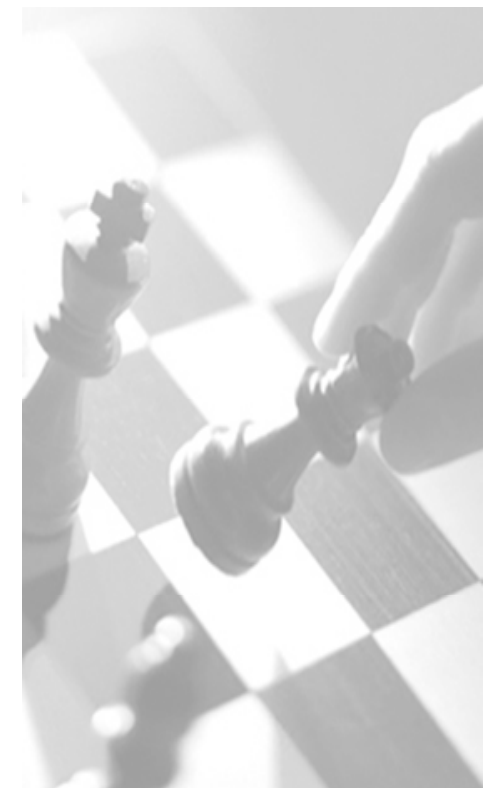




\section{Hypotheses development}

We derive hypotheses relating to social background, cultural capital and habitus

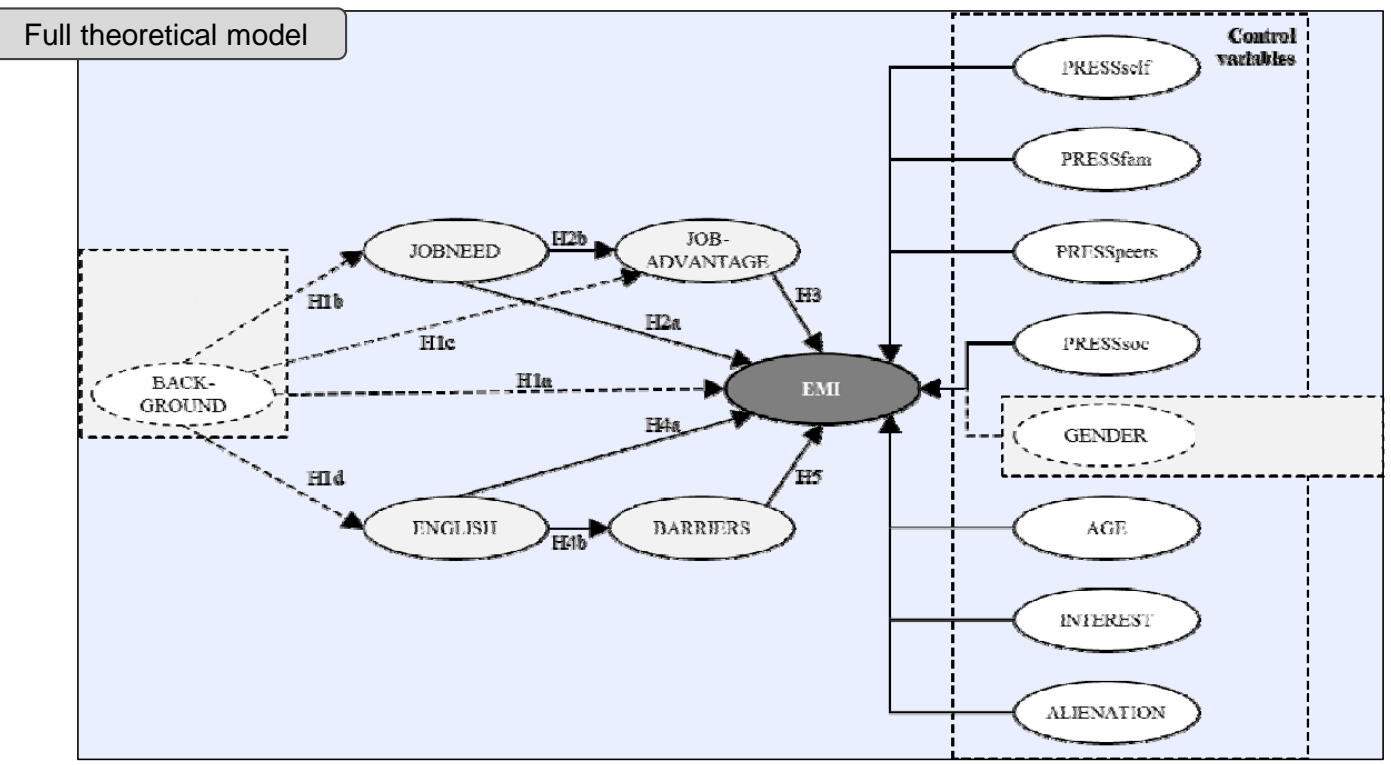

Why do lingua franca students choose English Medium Instruction?

A Bourdieuian Perspective

1 Motivation \& Background

2 Theoretical Frame

3 Hypotheses Development

4 Data \& Measurement

5 Findings \& Implications 


\section{Data \& Measurement}

We collected data via a questionnaire amongst AU first semesters

\section{Aspects of data collection and measurement}

- Students of BSc Economics and Business Administration in 2011

- Survey in a mandatory class

- 616 (937) Danish students with either DMI or EMI

- Development of questionnaire included pretesting with administrators, students and lecturers in several steps

- ...construct development after thorough literature review

- Analysis via PLS (Partial Least Squares)

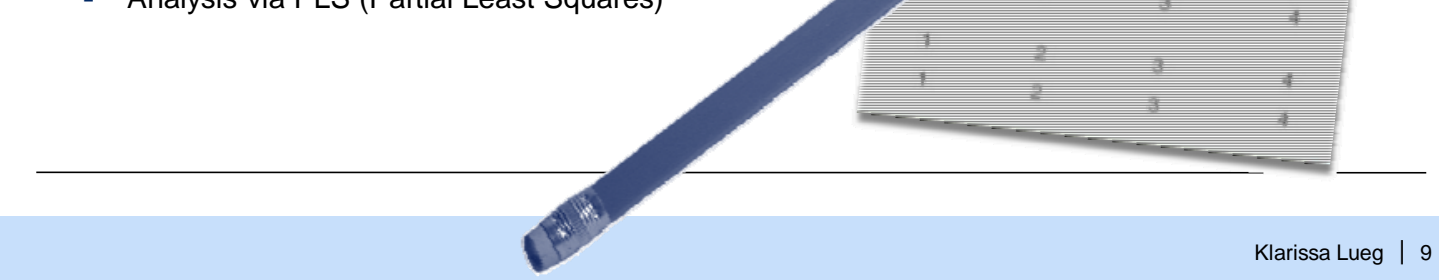

\section{Data \& Measurement}

We drafted ten constructs that represent possible reasons for choosing EMI

\begin{tabular}{|c|c|c|}
\hline JOBNEED & Does the student expect English to be a daily working routine? & \\
\hline JOBADVANTAGE & Does the student expect English skills to be an advantage at work? & \\
\hline ENGLISH & How do the students assess their own English proficiencies? & \\
\hline BARRIERS & What are the student's fears related to choosing EMI? & \\
\hline INTEREST & How high is the student's interest in cultures and languages? & \\
\hline ALIENATION & What is the student's attitude towards the diffusion of English in DK? & \\
\hline PRESSself & How high is the professional ambition of the students? & \\
\hline PRESSfam & How are the family's ambitions? & \\
\hline PRESSpeers & What is the student's peers influence on the language choice? & \\
\hline PRESSSOC & What is the student's view on English as symbolic capital? & \\
\hline
\end{tabular}




\section{Data \& Measurement}

Factor analyses show that constructs are well-defined

FamStatus

"HIS"-scale from Germany (1-4) for low, middle, upper middle and upper class.

EMI (English as medium of instruction choice)

Binary variable ( 0 = Danes choosing Danish; 1 = Danes choosing English)

Factor 1 CapabilityENG

V015 I speak English fluently.

V016 I write English fluently.

V017 I understand English without any problems.

V018 I speak English better than the average Dane.

V019 I speak English better than the average student at AU.

V020 I speak English better than the average non-English-native student around the world (Europe, Asia...).

Factor 2 Xenophobia / Alienation

033 "English harms the Danish language."

V034 "English harms the Danish culture."

V037 "English harms the Danish identity."

V038 "There is too much English spoken in Denmark."

V041 "Danish universities are too 'Anglo-Americanized'."

Factor 3 JobAdvantage

O49 I think that having studied in English is an advantage for job applications.

VO5O I think that having studied in English makes one more qualified than studying in Danish.

V051 I think that having studied in English increases job security.

V052 I think that having studied in English increases the chances for a higher salary.

V054 I chose to English program to improve my English skills.

Factor 4 JobNeed

V045 In my future career, I expect to communicate in English with customers and suppliers

V046 In my future career, I expect to communicate in English with direct colleagues (incl. superiors)

V047 In my future career, l expect to communicate in English with headquarter of the company

V048 In my future career, I expect to communicate in English with other strategic business units of the company

Factor 5 Barriers

012 It would be easier (harder) for me to engage in classroom discussions if the instruction language was Danish (English).

V013 It would be easier (harder) for me to understand the course content if the instruction language was Danish (English).

V014 It would be easier (harder) for me to get a good grade if the instruction language was Danish (English).

Why do lingua franca students choose English Medium Instruction?

1 Motivation \& Background

2 Theoretical Frame

3 Hypotheses Development

4 Data \& Measurement

5 Findings \& Implications 


\section{Hypotheses development}

We derive hypotheses relating to social background, cultural capital and habitus

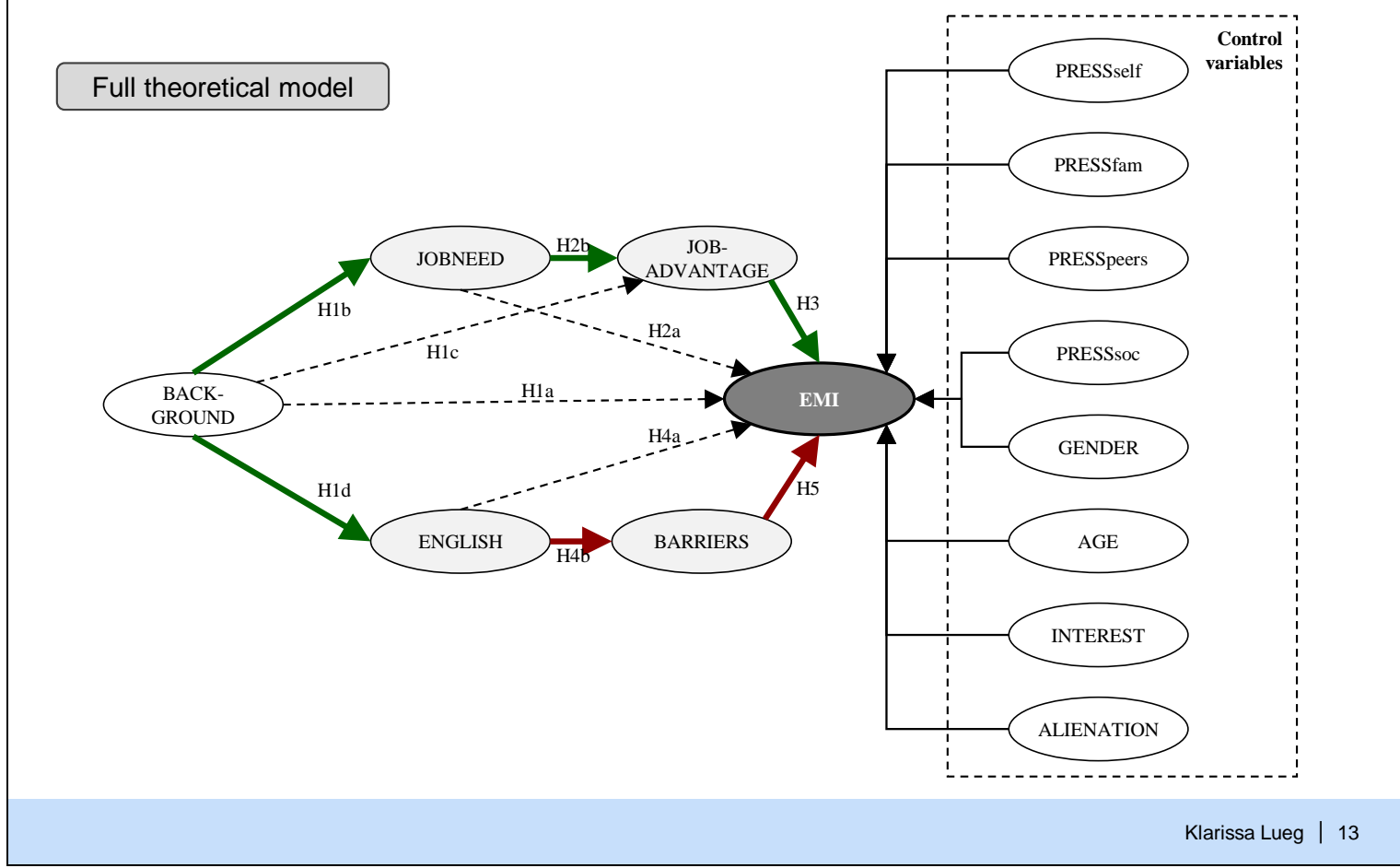

\section{Theory transition}

Connecting Bourdieu's constructivist structuralism and pragmatic constructivism

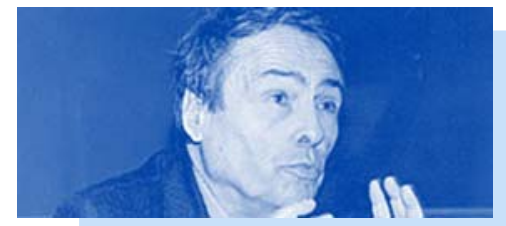

- Seemingly endless interdependency between agency and structure (perceived as deterministic)

- Doxical reproduction via manifestation and recognition of symbolic capital

$\rightarrow$ Group a: self-selection against

$\rightarrow$ Group B: opting for EMI

- Implication: Deconstruct the symbolic capital, in this case the value and prestige of EMI

- Nearly impossible within a management perspective

- No clear framework/constructs for deconstruction of symbolic power

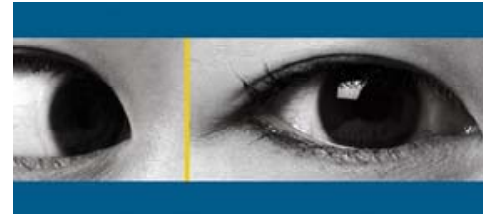

- Framework needed within the school of constructivism...

- ...yet must recognizes certain management and organizational facts (organizational frame)

- Step-by-step-framework (construct causality) understand agency

- Given: a set organizational frame)

$\rightarrow$ Pragmatic Constructivism 


\section{Implications for policy makers}

What are the implications for policy makers, from the PPC perspective?

- English IS the European lingua franca, English IS dominant in management education

- Chances to choose EMI are $50 \%$ higher if a student is from a higher stratum (given same average grades)

- EMI serves as distinction

- The effect is "hidden" (indirect) through habitus and cultural capital

- Low-stratum females also seize the opportunity

- Pressure from peers is more important for students from lower social backgrounds, families matter for high-stratum males

FACTS

VALUES

- Equal opportunities

- High quality of content

- Pedagogics in education

- Local roots, international orientation
- Devaluating/deconstructing EMI is not an option $\rightarrow$ possibility is to deconstruct some misunderstandings that come with it

- Higher absolute English proficiency will not help, the barriers must be torn down

- Translate continental business tradition

- Avoid "undergraduate MBA"-industry

- Explore construct causality of actors: - Gendered strategies

- Self-efficacy, reflexive practice

- Clarify that use of English literature necessary (most sophisticated)

- Explain individual benefits to lower strata students

- De-emphasize "Oxford English" in course descriptions, oral exams etc.

- Demonstrate equal opportunities for the "man on the street" to lower political resistance 


\section{References}

Lueg, K. 2011. Habitus in the Classroom: the Relevance of Student Heterogeneity and Departmental Culture for Learner-Oriented Didactics in Teaching Sociology. Journal of Social Science Education, 10(2): 29-38.

Lueg, K. 2012. Habitus, Herkunft und Positionierung: Springer.

Lueg, K. 2013. The family of constructivism and the contribution of a pragmatic dimension. Proceedings of Pragmatic Constructivism, 3(1): 49-51.

Lueg, K., \& Lueg, R. 2012. Why do students choose English as medium of instruction (EMI) in their home country? A socio-cultural perspective on non-native speakers, 19th NIC Conference on Intercultural Communication. Aarhus.

Lueg, K., \& Lueg, R. 2013. Why do lingua franca students choose English medium instruction? A Bourdieuian perspective. Proceedings of the 22nd Nordic Academy of Management Conference: 72-73.

Lueg, K., \& Lueg, R. 2014. Why do students choose English as a medium of instruction? A Bourdieusian perspective on the study strategies of non-native English speakers. Academy of Management Learning \& Education (forthcoming).

Petersen, M., Fage-Butler, A., \& Lueg, K. 2012. Public signs at the international university: some blind spots, The 19th NIC conference on intercultural communication. Aarhus, Danmark. 